\title{
A NEW GENUS AND SPECIES OF ANTHICIDAE
}

\section{FROM WESTERN UNITED STATES}

\author{
BY FLOYd G. WERNER \\ University of Arizona, Tucson
}

The first specimen of the interesting beetle described here was taken by Dr. W. L. Nutting and the author under dried flakes of mud on an alkali flat in Nevada in 1950. A diligent search in this rigorous habitat resulted in our obtaining one specimen alive, another dead and broken up, a living and a dead specimen of Tanarthrus salinus Lec. and one or two living spiders. There was evidence of other insects, present mostly as fragments. Most of these seemed to belong to groups that would have blown in from surrounding areas. A second living specimen was taken by $\mathrm{H}$. B. Leech in sand dunes near Stovepipe Wells, in Death Valley. The two collections indicate a rather extensive range for the species in the West, possibly confined to extreme desert areas.

Despite the shortened elytra, this insect is quite obviously an Anthicid. On first appearance it might be linked with such an insect as Tanarthrus brevipennis Csy., a species which also has abbreviated elytra. There are several striking points of difference. The present insect is much more slender than any known species of Tanarthrus. It has the last segment of the antennae entire and normal, without the groove that gives the illusion of dividing the last segment into two in Tanarthrus. There are major differences in the internal sac of the male genitalia. All the species of Tanarthrus except T. salinus have been examined and they have heavy spines on the internal sac and lack any specialized armature around the gonopore. The present insect lacks spines on the internal sac and has a peculiar structure associated with the gonopore, completely unlike any found elsewhere in the family, at least as it is represented in North America. The general shape of the genitalia is similar in the two genera. It seems 
best to designate this as a new genus and place it near Tanarthrus, but with some doubt as to its affinities.

\section{Leptanthicus gen. nov.}

Slender and flattened, with short elytra that leave the main part of the abdomen exposed. Metathoracic wings present but folded under the elytra in repose. Antennae normal and with the last segment not divided into two apparent segments by a groove. Mouth parts apparently normal, with the last segment of the maxillary palpi not expanded or otherwise modified. Pronotum rather slender, without any obvious modifications. Mesosternum not expanded laterally, the margins straight and ending near the outer edges of the mesocoxae. Legs not modified in the male, with two spurs on all the tibiae. Male genitalia without separate parameres, slender and pointed as in Tanarthrus. Internal sac without spines but with a complex and unique structure around the gonopore. Type of genus Leptanthicus staphyliniformis sp. nov.

\section{Leptanthicus staphyliniformis sp. nov}

Holotype $\hat{o}$ : almost uniformly brown in color, with darker abdomen and paler elytra, antennae, palpi, tibiae and tarsi. Surface generally finely punctured, with short and fine but moderately dense pubescence, not conspicuous except under some magnification and with longer, erect tactile setae scattered over the dorsal surface of the body. Length, to tip of elytra $1.97 \mathrm{~mm}$., to tip of abdomen ca. $2.68 \mathrm{~mm}$. Width: head $0.46 \mathrm{~mm}$., pronotum $0.41 \mathrm{~mm}$., and elytra ca. $0.56 \mathrm{~mm}$.

Head narrowly quadrate, flattened, the disc almost flat, $0.51 \mathrm{~mm}$. long to base of clypeus and $0.46 \mathrm{~mm}$. wide. Surface subopaque because of moderately dense but fine microreticulation; pubescence short, about $0.02 \mathrm{~mm}$. long, mostly subdecumbent and slightly curved, fine and directed toward the midline on the disc. Eyes small, $0.17 \times 0.13$ mm., placed well onto the sides and protruding only slightly from the sides of the head; with short, erect pubescence. Fronto-clypeal suture distinct though short. Bases of antennae separated by $0.18 \mathrm{~mm}$. Clypeus fairly broad, 0.23 
$\mathrm{mm}$. wide, $0.08 \mathrm{~mm}$. long, with a pair of obscure teeth on its anterior margin and a pair of slight angulations near the sides; setae longer, ca. $0.08 \mathrm{~mm}$., slightly curved and projecting forward. Labrum largely concealed by the clypeus from above, evenly rounded. Mandibles projecting beyond labrum, pointed and bifid at the tip, the upper tooth the longer. Maxillary palpi fairly large, the last segment $0.13 \times 0.08 \mathrm{~mm}$., obliquely truncate. Labial palpi very small. Antennae submoniliform, $1.06 \mathrm{~mm}$. long, with numerous erect setae. Measurements (in $0.01 \mathrm{~mm}$., base to apex) : $15 / 8,10 / 6,9 / 5,8 / 5,8 / 5,8 / 5,8 / 5,8 / 5,9 / 6,8 / 6$, $14 / 6$. The second segment is relatively large, the last bluntly pointed.

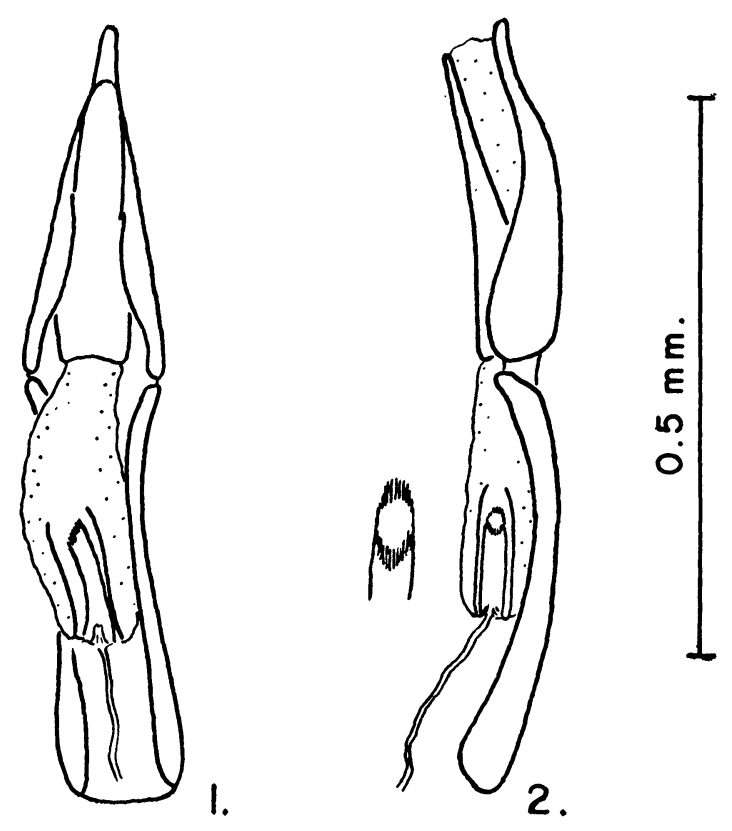

Figure 1. Leptanthicus staphyliniformis sp. n. Genitalia of holotype $\hat{o}$. Fig. 1. Ventral view as the genitalia lie in the abdomen. Fig. 2. Lateral view and enlarged detail of apex of gonopore armature.

Pronotum $0.51 \mathrm{~mm}$. long, 0.33 wide at base, 0.20 at collar and 0.44 at the widest point about $1 / 5$ from the 
apex. Sides almost straight to the widest point, then rounding to collar. Disc flattened, with pubescence similar to that of head but surface more deeply microreticulate. Scutellum fairly small, rounded. Elytra subparallel, 0.95 $\mathrm{mm}$. long, $0.46 \mathrm{~mm}$. wide at humeri, ca. 0.56 at widest. Apices obliquely truncate, individually rounded at the suture. Surface smoother than head; pubescence moderately dense, suberect, slightly curved, fine. Three full segments of the abdomen are left exposed, plus the pygidium. These are well sclerotized and separate from each other. They have pubescence similar to that on the elytra but sparser. The first two exposed tergites are subquadrate and delimited on the sides by the exposed edges of the sternites; both have a pair of dense patches of decumbent, medially directed pale pubescence near the middle, the patches on the anterior segment much the larger. Third exposed segment reaching sides of body, with only a very narrow edge of the sternite visible, larger than the first two, somewhat arched and rounded behind. Pygidium barely visible, the edge rounded and slightly beaded.

Surface and pubescence below similar to that on dorsum of abdomen. Prosternum a flattened, hexagonal plate, with a point extended back between the procoxae. Mesosternum not expanded, forming a straight line with the medial edge of the mesepisternum, the lateral edge of which extends dorsally into a narrow lobe anterior to the base of the elytra, this lobe following the body contour and not provided with long setae on its free edge. Metasternum flattened but quite normal. Fifth visible abdominal sternite truncate apically, the edge very gently excavated. Legs apparently normal, moderately slender, paler than the body except for the femora, tips excluded. Pubescence on legs moderately dense, subdecumbent. Tibiae with two, apparently simple, slender apical spurs. Tarsal claws slender, simple. Tarsal segments simple, the penultimate indistinctly lobed beneath. Measurements of metathoracic leg in $0.01 \mathrm{~mm}$.: femur $56 \times 13$, tibia $54 \times 8$, tarsus 33 $\times 5$.

Paratype $\circ$ : a larger and darker specimen, $2.35 \mathrm{~mm}$. long to tip of elytra, ca. 3.12 to tip of abdomen. Head 
$0.59 \mathrm{~mm}$. long, 0.49 wide; pronotum $0.61 \mathrm{~mm}$. long, 0.42 wide; elytra $1.15 \mathrm{~mm}$. long, 0.56 wide at humeri, ca. 0.77 at widest. Differences that are of a secondary sexual nature are: third exposed abdominal tergite not as arched; pygidium absent; fifth visible abdominal sternite large, the hind margin almost evenly rounded, slightly ogival. Other differences that may indicate individual or population variation are: hind margin of head slightly excavated at the middle; elytra and appendages almost as dark as rest of body and the pubescent patches on the abdominal tergites dark. The scattered, erect tactile setae are ca. $0.06 \mathrm{~mm}$. long in the holotype, ca. $0.13 \mathrm{~mm}$. in this specimen and therefore much more conspicuous. The labrum extends beyond the clypeus when viewed from above.

Holotype: o - Mud flats next to alkali lake at Salt Wells, Churchill Co., Nevada, May 31, 1950, F. G. Werner and W. L. Nutting. Deposited in the M. C. Z. Paratype: 1 \& - Sand dunes near Stovepipe Wells, Death Valley, Inyo Co., California - April 2, H. B. Leech, in the Calif. Acad. Sci. 

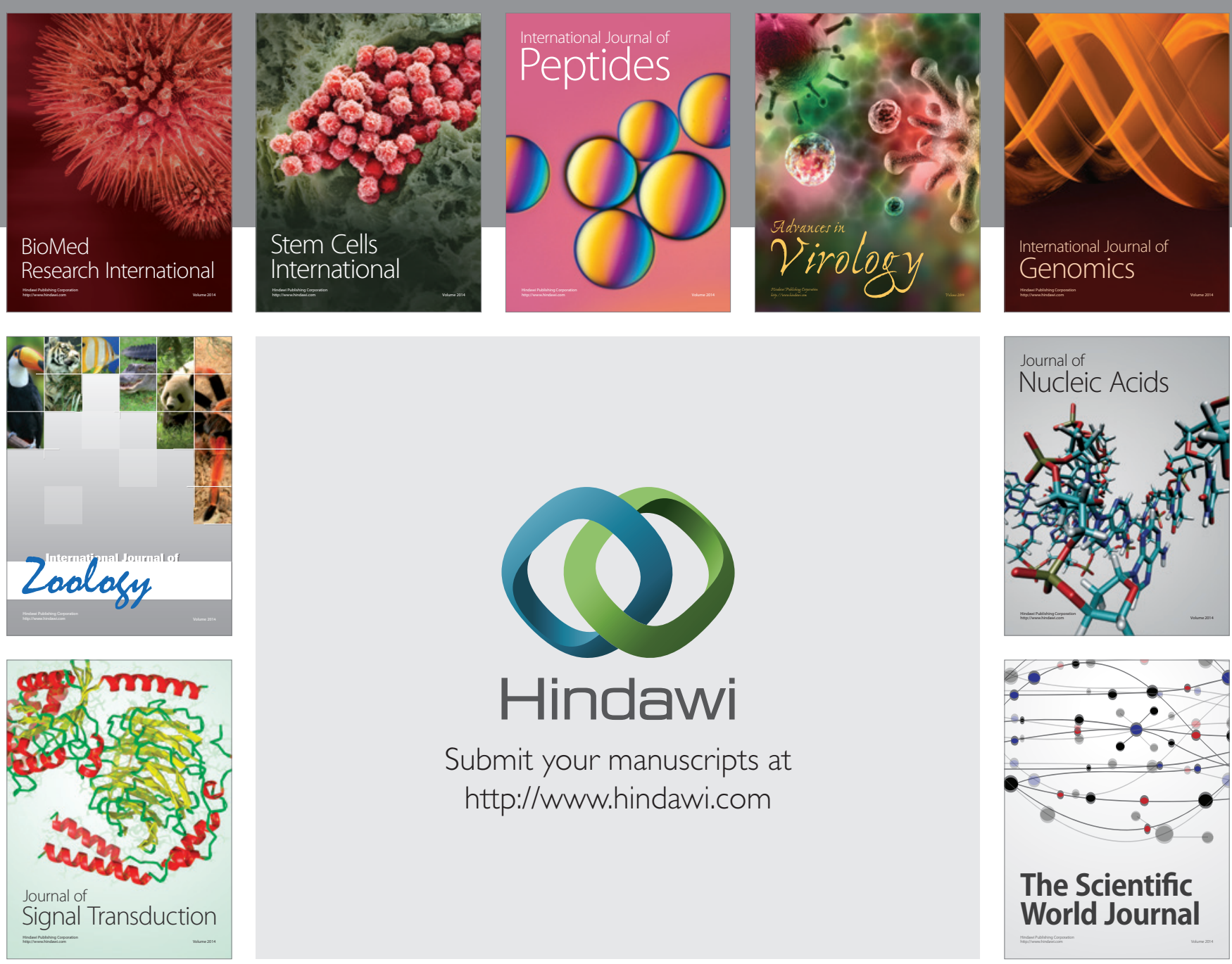

Submit your manuscripts at

http://www.hindawi.com
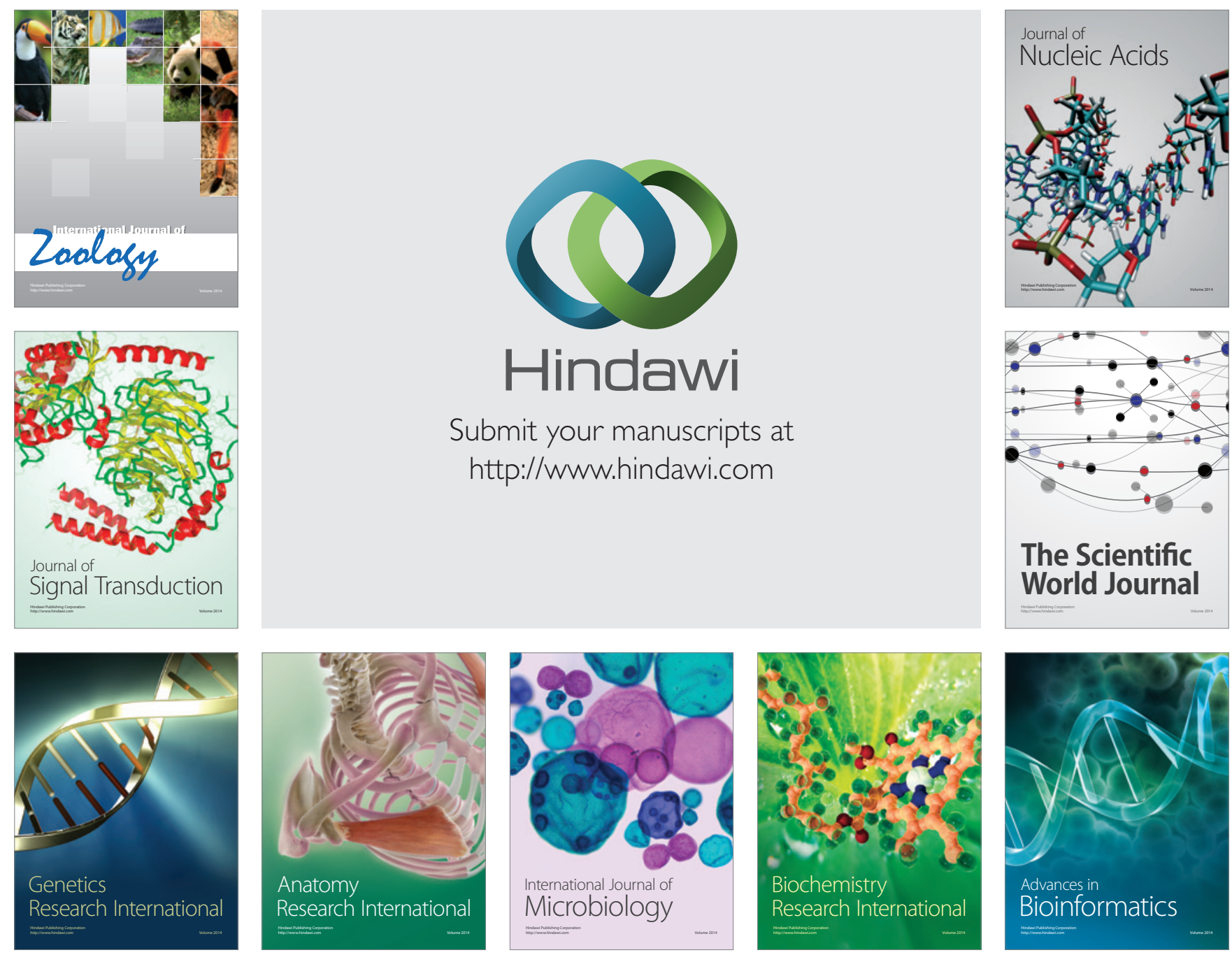

The Scientific World Journal
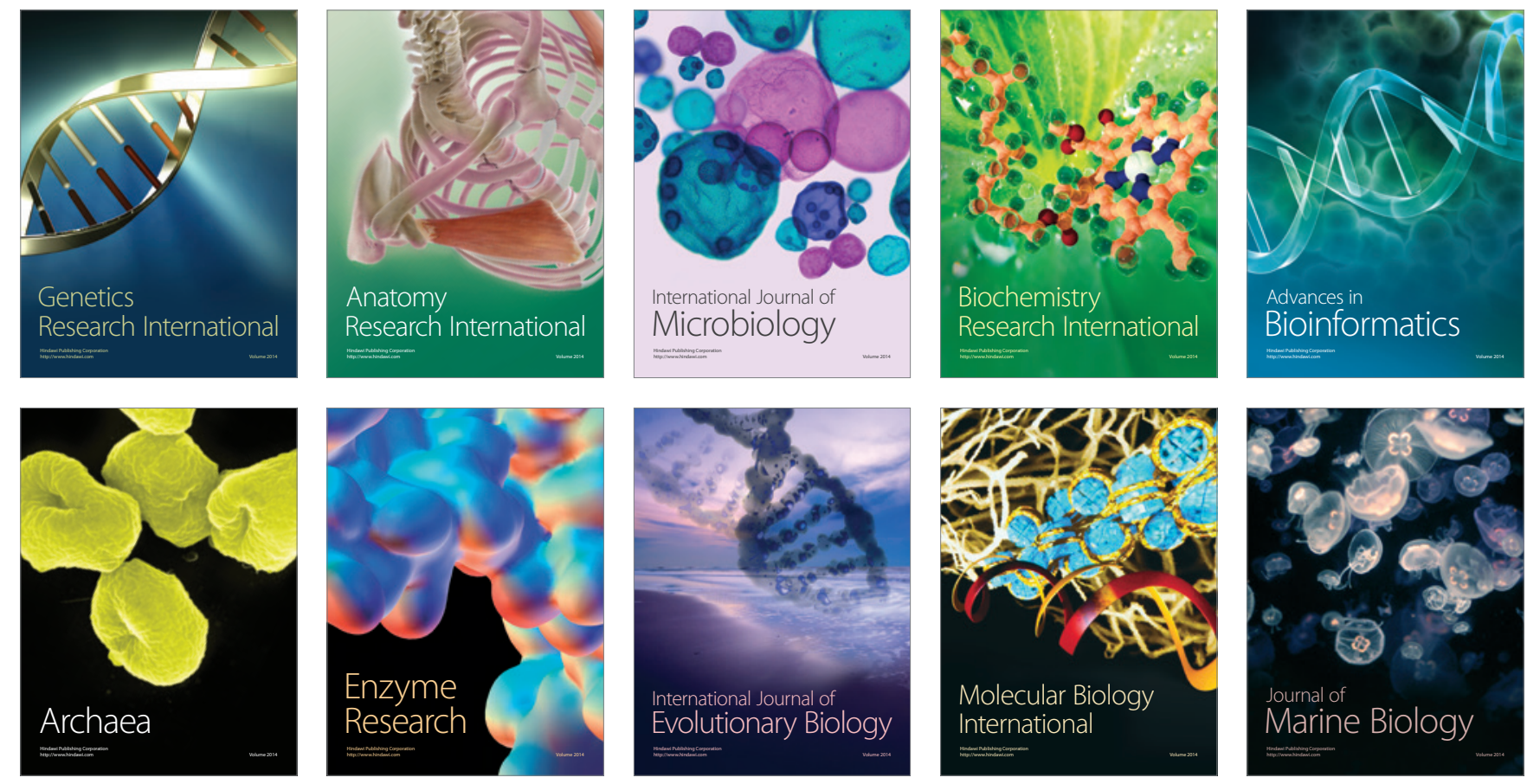